\title{
EDITORIAL
}

\section{¿Significance Statements Communicate Our Science More Widely}

\section{KEYWORD: Editorial}

As our colleague and Monthly Weather Review Chief Editor David Schultz puts it in a recent editorial, "We write our journal articles primarily for other researchers in atmospheric science. These articles have received increasing exposure and attention through the media and social media, particularly with a greater proportion of studies being freely available upon publication due to open access. Thus, the general public, as well as scientists in other disciplines, are increasingly coming into contact with our peculiar means and style of communication" (Schultz et al. 2020). The same applies for the community this journal serves. Schultz et al. go on to illustrate the increasing exposure and attention with an example, and summarize AMS's approach to communicating in this new way:

For example, an article about a Polish outbreak of severe weather published in Monthly Weather Review (Taszarek et al. 2019) was our most downloaded article over the past year (over 20000 times and counting, 10 times more than the No. 2 article) because of posts on the Polish Storm Hunters Facebook page when the paper was first published and on the anniversary of the storm. These posts were widely shared and commented upon by lay people who were often deeply and personally affected by the power of the storm. Such examples show the power of social media to drive traffic to scientific articles.

Such increases in traffic allow us to reach different audiences interested in our science. In addition to harnessing the power of social media to spread news of our work, we can better communicate to the general public what we have done and why it matters, which will also help broaden the potential readership of our scientific journals. To help share our science in this way, the AMS Publications Commission approved the use of plain-language "significance statements" in a pilot study at two of our sister journals: Weather and Forecasting and Weather, Climate, and Society (Lackmann 2020; Huntington and Lackmann 2020). Significance statements are a way to make our articles more readable to the general public or scientists from other disciplines. As Huntington and Lackmann (2020) elaborate,

much if not most published research is funded at least in part from public sources. In addition to the requirements of the particular funding agency, we as researchers have an obligation to show society at large what we are doing and why our work justifies the money that society allocates for that work. Significance statements can help to show how our papers contribute to understanding our world and why that understanding is useful to us all.

More specifically, the AMS provides guidance for those considering writing a significance statement, as outlined below.

A significance statement is not supposed to be a plain-language repeat of the abstract. It should focus on why the work matters and provide additional context for why the work is relevant to science and society. Significance statements will be peer-reviewed and will appear after the abstract in the published paper. The statements must answer the following questions in 120 words or less, without jargon or technical wording:

1) What is the purpose of the work?

2) What are the key findings, and why do they matter?

3) What follow-up science is suggested by these findings (optional)?

Authors opting to provide a significance statement with their manuscript should include it immediately after the abstract in the manuscript file with an unnumbered section title of "Significance Statement.

Further information about significance statements, guidance about how to write one, and examples can be found on the AMS web page: https://ametsoc.org/SignificanceStatements.

¿ Denotes content that is immediately available upon publication as open access. 
Including a significance statement is presently optional for submissions to the Journal of Atmospheric and Oceanic Technology. Not all articles need a significance statement, but we encourage authors of even the most highly technical articles to try to communicate the significance of their results to a broader audience. Doing so not only helps our readers understand the value of even esoteric science, but helps scientists expand the audiences that they can communicate with.

Luca Baldini and William Emery Chief Editors, Journal of Atmospheric and Oceanic Technology

\section{REFERENCES}

Huntington, H. P., and G. M. Lackmann, 2020: Stating the significance of our work. Wea. Climate Soc., 12, 645, https://doi.org/10.1175/WCAS-D-20-0066.1.

Lackmann, G. M., 2020: Broadening the scope and impact of Weather and Forecasting. Wea. Forecasting, 35, 3, https://doi.org/10.1175/WAF-D-19-0246.1.

Schultz, D. M., G. M. Lackmann, H. P. Huntington, and M. A. Friedman, 2020: Significance statements broaden our audience. Mon. Wea. Rev., 148, 3569-3570, https://doi.org/10.1175/MWR-D-20-0193.1.

Taszarek, M., and Coauthors, 2019: Derecho evolving from a mesocyclone-A study of 11 August 2017 severe weather outbreak in Poland: Event analysis and high-resolution simulation. Mon. Wea. Rev., 147, 2283-2306, https://doi.org/10.1175/MWR-D-18-0330.1. 